\title{
Using Real-time Data and Corrective Teacher-feedback as a Mechanism to Improve Children's Reading Skills: An Exploratory Study in the Millennium Village Site of Bonsaaso, Ghana
}

\author{
Radhika Iyengar $^{1}$, Sarah Muffly ${ }^{1}$, Charles Akomaning-Mensah ${ }^{1}$, Alia Karim ${ }^{1}$, Prabhas Pokharel ${ }^{1}$, Sarayu Adeni ${ }^{1}$ \\ ${ }^{1}$ Earth Institute, Columbia University, USA \\ Correspondence: Radhika Iyengar, Earth Institute, Columbia University, USA.
}

Received: May 5, 2016 Accepted: May 17, $2016 \quad$ Online Published: June 21, 2016

doi:10.11114/jets.v4i9.1593 URL: http://dx.doi.org/10.11114/jets.v4i9.1593

\begin{abstract}
Educational outcomes across multiple countries show large gaps between children's grade level curricular expectations and the actual learning levels of children. This paper discusses findings from an early grades literacy study and attempts to explore factors that potentially improve the English language learning results of Grades 3 and 4 learners in Bonsaaso, Ghana. The study was conducted in five schools, and the teachers were randomly selected into treatment and control groups. This is a quasi-randomized study. The objective of the study is to understand the components and processes that improve learning. The treatment included teacher training, constant feedback using real-time data and supervision, discussions of student-learning outcomes, materials development, corrective feedback to students and lesson plans. Overall, the percentage of the learners able to read as a result of this instructional treatment almost doubled compared to the control group; $34 \%$ of the students in the treatment group were classified as able to read at the end of the study compared to $18 \%$ in the control group. However, majority of the students were unable to read simple sentences. The classroom observations describe some of the classroom management and teaching techniques that could enhance learner performance.
\end{abstract}

Keywords: real-time data, student learning outcomes, teacher feedback, teacher supervision, Ghana, primary schools, English education

\section{Introduction}

Since the implementation of the Millennium Development Goals-including that of universal access primary education - began in 2000, a hidden crisis in education has been uncovered: the problem of educational quality. The priorities in the international discourse have, accordingly, moved from enrollment to learning. This debate centers on the idea that there has been a lot of progress in improving enrollment rates, yet there has been very little emphasis on the learning levels of children who attend school regularly (Center for Universal Education at Brookings, 2011). Recent evidence on learning levels shows that this trend is visible in several countries (Beatty \& Pritchett, 2012). To address this need, the UN Secretary General announced the Education First campaign, which targets access to education in conjunction with improving learning quality and fostering global citizenship.

In East Africa, learning surveys have been undertaken that classified student ability to calculate and to read texts of various lengths (Uwezo Kenya, 2012 \& Uwezo Uganda, 2011). Recent results suggest that in Kenya, 11 out of 100 children in class ${ }^{1} 8$ still cannot do simple class 2 division problems (Uwezo Kenya, 2012) ${ }^{2}$. Furthermore, 7 out of 100 could not read a simple story in either English or Kiswahili. Uwezo tests results from Kenya showed that nationally only 3 out of 10 children in class 3 could read a second-grade text. In Uganda at least 9 out of every 10 (92\%) of all third graders in $\mathrm{P} 3^{3}$ were unable to read a second-grade story in English. And of those third graders who could read a

\footnotetext{
${ }^{1}$ In Kenya, grades and standards are called class.

${ }^{2}$ Uwezo, meaning 'capability' in Kiswahili, is a four-year initiative that aims to improve competencies in literacy and numeracy among children aged 6-16 years old in Kenya, Tanzania and Uganda

(http://www.uwezo.net/).

${ }^{3}$ In Uganda, P3 or Primary 3 is equivalent to Grade 3 or Standard 3 in other countries.
} 
second-grade story in English, about 10\% failed to understand it. Results from UWEZO Tanzania (2011) were also discouraging. Only 3 out of 10 third $^{4}$ graders could read a basic story in Kiswahili and only 1 out of 10 Standard 3 pupils could read a basic story in English. The results were no better in mathematics. Only 3 out of 10 students could add, subtract and multiply (UWEZO Tanzania, 2011).

Such results are repeatedly seen in multiple countries. In the Gambia, Mozambique, and Nepal, more than $50 \%$ of the children are unable to read a single word of one-paragraph story after two years of schooling (Pritchett \& Banerji, 2013). Data from the Southern and Eastern Africa Consortium for Monitoring Education Quality (SACMEQ) showed that less than $40 \%$ of the children attending Grade 6 have reached the reading proficiency levels required at that grade level in countries like Malawi, Zambia, Namibia, Mauritius, Zimbabwe and Kenya (Pritchett \& Banerji, 2013). Simple tests similar to Uwezo were administered to children between 6 to 14 years old in rural India. Not only are children underperforming at grade level, but the overall learning levels also have decreased over the past years (ASER, 2011). ASER shows that $50 \%$ of the children in Standard $5^{5}$ are even unable to read a Standard 2-level text (Chavan \& Banerji, 2012). This means that half of the children in grade 2 have failed to learn basic reading skills and may not acquire them in the following three years.

This paper attempts to explore the factors that have the potential to improve English-language learning results of primary school children in Ghana. More specifically, it discusses the findings of a literacy assessment study conducted with students in Grades 3 and 4 in the Millennium Villages cluster in Bonsaaso, Ghana. The paper starts by explaining the rationale of the study followed by the Millennium Villages approach and context. This section is followed by a literature review on the supply-side factors that can potentially improve learning results. Next, the study design and implementation are discussed, followed by a description of the intervention package. The paper then presents an analysis of the study results and other observations. The paper concludes by discussing the challenges and successes of the study and ends by suggesting ways of scaling-up this approach based on the lessons learned through this exploratory study.

\section{Materials and Methods}

\subsection{Geographic Context}

This study housed within The Millennium Villages Project (MVP), a project whose concerted effort is to show that the Millennium Development Goals can be attained in sub-Saharan Africa through targeted, multi-sectoral interventions. In the education sector, MVP collects monthly data from schools on key indicators. These indicators include literacy levels, student and teacher attendance and basic school infrastructure indicators. Data from Bonsaaso, Ghana have consistently shown low literacy levels. This study was, designed to understand the problem of low learning levels in the five schools located in the southern part of the cluster, and to evaluate the effects of a package of interventions addressing basic literacy of primary school students in Bonsaaso. It included administering literacy assessments and recording the learning results on mobile phones. It also included classroom observations and supervision visits by the Ghana Education Service (GES) staff and the MVP staff, and teacher training that involved demonstrating corrective feedback to students, classroom management techniques, creation of teaching and learning materials (TLM) and content delivery techniques.

In addition to evaluating the effects of the remedial education interventions, an important component of this study was the use of mobile data capturing technology; it recorded real-time information, thereby supporting timely planning of appropriate interventions. A major part of the study was the creation of online Literacy Report Cards summarizing the results of the assessments. These were shared with schools, communities and officials from the Ghanaian Ministry of Education (MOE) within days of data collection. By processing and sharing test results in a timely manner, the study aimed to facilitate the implementation and evaluation of activities addressing learning gaps.

Until 2002, Ghanaian language policy decreed that the lower primary grades would be taught in the local language, with English introduced progressively in the curriculum. By P3 (grade 3), students would spend the same amount of time learning English than the local language, and by the end of P3, they would be expected to be able to write simple sentences and read actual stories from textbooks, given the necessity of reading fluency for further learning. In 2002, however, the government changed the policy and mandated English-only instruction starting in P1 (Owu-Ewie, 2006). As of 2009, the policy is to teach up to primary grade 3 in local language, and then fully transitioning to English by grade 4. However, English is taught as a subject since Grade $1^{6}$. Therefore, this study assessed basic English literacy

\footnotetext{
${ }^{4}$ In Tanzania, Standard 3 is equivalent to Grade 3 in other countries.

${ }^{5}$ Grade is called Standard (Std.) in India.

${ }^{6}$ USAID and Ministry of Education Ghana Education Service National Education Assessment Unit (2014). Ghana 2013
} 
skills of students enrolled in P3 and P4, in order to identify learning gaps that could be addressed through the design of effective remedial education activities.

\subsection{Background about the Millennium Villages Project Cluster in Bonsaaso}

Bonsaaso is located in the Amansie-West District of the Ashanti Region of Ghana. Nearly $70 \%$ of community members live on less than $\$ 1$ a day. Just $4 \%$ of households have access to improved sanitation, and there is little access to health care, electricity, and communication services, as well. There are six villages in Bonsaaso with a population of about 35,000 people residing in about 6500 households. There are currently 24 primary schools with nurseries, and four stand-alone nursery schools in small communities serving the school-going population in the Bonsaaso cluster.

\subsection{What Improves Learning Levels: Evidence from Existing Literature}

There is much research that defines how children learn new information and skills, particularly in low-income environments (Abadzi, 2007). The review below focuses on economically oriented studies that addressed "supply side" factors on teachers and pedagogy. The articles selected are either reviews themselves or are original articles based on evidence from developing countries.

\subsubsection{Teachers and Teacher Quality}

Efforts to improve teacher performance in low-income areas have been ambivalent. Few if any studies have found significant and positive impact of teacher training on student learning outcomes (Muralidhararan, 2012). Also few if any studies have found a correlation between teacher salaries and gains in student test scores. The impact of reduced pupil-to-teacher ratio on student outcome is mixed as well (Muralidharan, 2012). Mukerji and Walton (2010) shared results of a Kenya-based study (Duflo et al, 2006) where additional teachers were assigned to schools, while the control schools received no additional teacher. The groups of schools were randomly selected where grade 1 children were grouped by learning level based on a pre-test. In control schools, classroom groups were made without predetermined criteria. Mukerji and Walton (2010) show that merely reducing the class size by adding an extra teacher had no effect on the test scores of the students. Only when the school committee members monitored the teachers did teachers exert more effort. However, the learning gap between the contractual teachers and regular teachers did not substantially decrease.

Another strategy has been to hire community-based local teachers. Hiring local teachers for a short-term basis to supplement regular formal teachers has shown to improve test scores both in Kenya and India (Duflo, Dupas, \& Kremer, 2011; Banerjee, S. Cole, E. Duflo, \& Linden, 2007 as cited in Kremer, Brannen, \& Glennerster, 2013). Monitoring teachers has also shown test score improvements. Research from India suggests that incentivizing teacher presence in class can improve test scores; one example was the use of cameras to monitor teacher presence in the classrooms (Duflo, Hanna, \& Ryan, 2012 as cited in Kremer, Brannen, \& Glennerster, 2013).

\subsubsection{Textbooks and Educational Materials}

Muralidhararan (2012) cites experimental evidence from Das et al. (2013) on the impact of a school grant program meant for purchase of inputs directly by students. The major input categories were books, stationery and writing materials, workbooks and practice books, and classroom materials. The results showed that there was a significantly positive impact on student test scores at the end of the first year; however the impact in the second year was close to zero, with the cumulative two-year effect being positive but non-significant. Perhaps households considerably reduced their own spending on their children's education in the second year of the program as a result of the additional funds made available by the school grant Muralidhararan (2012). Mukerji \& Walton's (2010) review shows that there is mixed evidence on the impact of instructional inputs such as reading materials and flipcharts on children's learning outcomes. However, they note that when these materials were combined with appropriate teacher training and support there was a positive impact on basic math and reading skills for the children. Mukerji \& Walton (2010) and Kremer, Brannen, and Glennerster (2013) note that in a study (Glewwe, Kremer \& Moulin, 2009) where the provision of free textbooks to primary and middle schools in Kenya helped the scores of the best students; however there was no impact on the weaker students. The authors concluded that textbooks helped those students who already knew how to read fluently and not the ones that needed remedial help in basic reading.

\subsubsection{Pedagogy}

Several studies show the effect of teaching practices on learning levels. One example is an evaluation of Pratham's (an Indian NGO) balsakhi program (Banerjee, Cole, Duflo, \& Linden, 2007). Children in Grades 3 and 4 who had not 
acquired basic reading and numeracy skills were taken out of the regular classroom for two hours for a special instruction with a balsakhi, a contract teacher. The program modestly improved student test scores by 0.28 standard deviations, with most of the gains coming from students at the lower end of the learning distribution.

Another study focused on communicating to the local village residents the status of learning among their children, and on the potential role that Village Education Councils (VECs) and local governments could play in improving learning (Banerjee, Banerji, Duflo, Glennerster, \& Khemani, 2007). It was expected that awareness of literacy rates would motivate the community to improve them. Surveys conducted after an information campaign surprisingly showed that the campaign did not have any effects on learning levels. However, when the campaign was matched with community volunteers conducting classes outside schools in the same villages, the literacy levels of 6- to 14-year-olds in the community improved. In this case, information alone did not have any impact on the learning levels (Banerjee, Banerji, Duflo, Glennerster, \& Khemani 2007).

In contrast to the above studies which have taken only one or two elements, the Bonsaaso study combines different pedagogical and management elements such as teacher training, constant feedback and supervision, discussions of student-learning outcomes, materials development, and lesson plans to understand the literacy challenge in a rural district in Ghana. This study includes a package of essential inputs that are required to improve learning. The objective of this study was not to identify which component has the maximum impact on learning, however, the study helps to understand a holistic more systemic set factors are needed to improve learning.

\subsection{Study Design and Implementation Plan}

Our study included one P3 and P4 class from each of the five schools located in the southern part of the Bonsaaso cluster. One of the two classes in each school was selected for the treatment group while the other served as a control class. Since the schools were from the same region, it is most likely the school and the student characteristics are on average similar. The classes were not divided based on the learning levels. Therefore the class constitution should roughly be the same in terms of learning levels. Each of the participating schools had one P3 class and teacher, and one P4 class and teacher. Thus, a total of 10 teachers (and their corresponding students) participated in the study. In each school the treatment and control teachers were selected randomly by flipping a coin. The five schools were selected to participate in the study using convenience sampling, based on the following criteria: first, all schools in the sample offered a full cycle of primary education (P1-P6); had one teacher for each grade; and had reading textbooks available. Second, all schools in the sample were receiving the same support by MVP. Table 1 shows the enrollment and number of teachers for the participating schools.

Table 1. Participating schools, student enrollment and number of teachers

\begin{tabular}{|c|c|c|c|c|c|c|c|}
\hline & & & & \multicolumn{4}{|c|}{ Study Participants } \\
\hline & Name & $\begin{array}{l}\text { Location (village } \\
\text { name) }\end{array}$ & $\begin{array}{l}\text { Pupils } \\
\text { Class } 3 \\
\end{array}$ & $\begin{array}{l}\text { Pupils } \\
\text { Class } 4\end{array}$ & $\begin{array}{l}\text { Teachers } \\
\text { class } 3\end{array}$ & $\begin{array}{l}\text { Teachers } \\
\text { class } 4\end{array}$ & $\begin{array}{l}\text { Total } \\
\text { Teachers }\end{array}$ \\
\hline 1 & \multirow{6}{*}{$\begin{array}{l}\text { Bonsaaso D/A } \\
\text { Aboaboso D/A } \\
\text { Akyekyerekrom } \\
\text { D/A } \\
\text { Apenimadi D/A } \\
\text { Yawkasakrom } \\
\text { D/A }\end{array}$} & Bonsaaso & 46 & 31 & 1 & 1 & 2 \\
\hline 2 & & Aboaboso & 43 & 37 & 1 & 1 & 2 \\
\hline 3 & & Akyekyerekrom & 33 & 31 & 1 & 1 & 2 \\
\hline 4 & & Apenimadi & 25 & 22 & 1 & 1 & 2 \\
\hline \multirow[t]{2}{*}{5} & & Yawkasakrom & 17 & 14 & 1 & 1 & 2 \\
\hline & & & 164 & 135 & 5 & 5 & 10 \\
\hline
\end{tabular}

All students enrolled in P3 and P4 in the five participating schools took part in the study. The same group of children was assessed in each testing round. Given the small sample size (5 schools and 10 teachers), we randomized teachers instead of schools to improve the likelihood of getting two groups with similar characteristics. That way, the number of randomized units was twice as big (10 teachers versus 5 schools). Teachers in the treatment group received training on effective techniques to teach reading.

The study consisted of three main phases: (1) development and testing of tools and data management systems, (2) baseline and midline data collection and implementation of remediation, and (3) end line data collection and analysis.

Since schools were selected using convenience sampling, the conclusions of the study are not representative of the entire population of schools in the Bonsaaso MVP site. Nevertheless, convenience sampling provides basic evidence and trends regarding the interventions being evaluated without the complications and costs of random sampling. The research team expected improved reading skills in the treatment schools at the end of the study as a result of the teacher-training package. Table 2 describes the data collection tools. 
Table 2. Data collection tools, content and sample size

\begin{tabular}{lll}
\hline Tool & Content & \multicolumn{1}{c}{ Subjects and Sample Size } \\
\hline Teacher Registration Form & $\begin{array}{l}\text { Basic characteristics of } \\
\text { participating in the study }\end{array}$ & $\begin{array}{l}10 \text { teachers (5 Grade } 3 \text { teachers }+5 \text { Grade } 4 \\
\text { teachers) }\end{array}$ \\
Reading Tests & Reading tests in English & 301 students (Grades 3 and 4)
\end{tabular}

Results of reading tests and basic characteristics of the student 301 students (Grades 3 and 4)

Checklist for supervisors to observe teachers, monitor implementation of key

Classroom Observation form strategies

5 'treatment' teachers observed

The Student Assessment Form took in the following information about the student: age, sex, school grade, and literacy level. It also scanned the bar code on the teacher's ID card, which allowed researchers to easily categorize assessments by teacher. Finally, the student assessment form noted whether the teacher in question had participated in a training session since the last assessment, which aided in monitoring the treatment group. The classroom observation form included sections on classroom environment and materials, teaching techniques used, and teacher-student interactions. These classroom observation forms tracked classroom inputs, implementation of content taught in teacher training, and teacher feedback to and interaction with students. Teachers received feedback, and future training content was adjusted based on classroom observations. The form allowed all observers to have a standardized mechanism for tracking their observations and checking for classroom requirements, while still leaving room for additional notes and comments at the observer's discretion. The Teacher Registration Form and the Student Assessment Form were programmed into Android phones for data collection using an open-source software program called Open Data Kit (opendatakit.org). Once the data was collected on the phones, they were directly sent to formhub.org, a data-management platform developed by the Sustainable Engineering Lab at Columbia University. From formhub, CSV files with the raw data could be downloaded for further processing.

\subsubsection{Test Design and Administration}

MVP monitors the reading and numeracy skills of primary school students using the tests and methodology developed by ASER in India and UWEZO in Africa ${ }^{7}$ MVP has adapted and programmed these tests for their administration using Android phones. The reading tests were developed in collaboration with curriculum and assessment experts from the national Education Ministries and follow existing government standards and benchmarks set per grade. They are simple yet robust, structured to take no longer than 10 minutes per child. These tests are individually administered to each child. The reading tests assess children's competency levels in four areas, including: letter recognition, words, paragraphs, and simple story comprehension. An UWEZO-style English literacy test was developed by Pratham for a Ghana MOE collaborative study (Ghana Teacher Community Assistant Initiative) ${ }^{8}$, and this test, along with others developed in collaboration with the Ghana MOE were used for this study. UWEZO/ASER's testing framework is given in Appendix 1, along with sample tests in Appendix 2. Children's scores reflect their highest reading level: reading a story (usually a set of 5-6 lines that are connected), paragraph (3-4 lines which are connected), word (6-7 words which are combination of simple, medium and complex words), letters (around 9-10 combination of letters from easily recognizable to complex. Students need to identify any 5). If the child is not able to read at all, he/she is kept in the "nothing or needs improvement" group. For the purposes of this study, MVP categorized children in the 'story' and 'paragraph' categories as 'children who can read', and children in the 'word,' 'letter' and 'nothing' categories as 'children who cannot read' in grade 2 .

The learning assessment was conducted three times for this study: baseline, midline and endline. All children in both the control and treatment classes were tested at each interval. Independent enumerators, who were not involved in the intervention, tested children from the assigned study teachers (both from control and treatment). During the test, the enumerator sat on a desk and a chair outside the class. The teacher sent one child at a time to the enumerator for the 10-minute-long assessment, so as not to disturb the whole class during testing. Enumerators carried one hard copy of each test to share with the child during the assessment. Test results, along with basic information about the child were captured on the phone using the Student Assessment Form. When conducting literacy assessments with students, the enumerator individually called up students, recorded the basic information, and pointed at items on the printed pages,

\footnotetext{
${ }^{7}$ In addition to working with Uwezo in East Africa, MVP partners with other NGOs and research institutions using the same approach. These institutions include Lartes in Senegal and OMAES in Mali.

${ }^{8}$ Please visit http://www.povertyactionlab.org/doc/ghana-conference-booklet for more details.
} 
letting the child point if reading confidence was demonstrated. Each child had roughly five minutes to show ability to read the assessment material. Those who were able to read fluently to story level were positively acknowledged in front of the class.

\subsubsection{Development of an Online Interface to Track Results}

In collaboration with the Sustainable Engineering $\mathrm{Lab}^{9}$ the project was able to develop an online interface to track and display the results. The data from formhub was processed into simple graphs that were displayed on the site: http://litreportcards.modilabs.org/about.html. The data was organized by treatment and control classes, disaggregated by grade level and displayed as "Literacy Report Cards" of the school. The interface is open to the public so that the results can be shared with a wider audience. All stakeholders, teachers, principals, MVP staff team and GES were able to review the data online within weeks of data collection. This helped the project to be more transparent and get more stakeholders to be involved. Since there was no internet access at the schools, printed copies of the Literacy Report Cards were distributed to school staff. This online interface was an efficient way of comparing the results between baseline, midline and end line, which helped to create a one-stop place that could display information in all stakeholder meetings, and any stakeholder interested in the study could visit the site and share as needed.

\subsubsection{Description of the Treatment}

The treatment involved working with selected teachers from primary 3 and 4 classrooms in the five selected schools, providing them with training on pedagogy and content, teaching and learning materials, sample lesson plans, and frequent monitoring and supervision. Throughout the treatment period, teachers were asked to adjust their subject teaching schedules to accommodate a 90-minute class period dedicated to English each day. Given the extremely poor results, all the stakeholders involved agreed that for the duration of this intervention, the formal curriculum would not be used, and supplementary materials, techniques, and activities would be implemented to catch students up to speed. Once they had reached the appropriate reading level for their grade, they would return to the formal curriculum. GES was willing to make changes in the regular school hours for this study. All the participating teachers and head teachers, acknowledging that literacy levels were very low and additional time focused on English literacy instruction was necessary, agreed upon this increased teaching time. The treatment group participated in training sessions devoted to explicit phonics instruction, using a guide developed by members of the Earth Institute education team. The training sessions were led by the Bonsaaso MVP education team, members of the Ghana Education Service (GES), and the Earth Institute education team.

\subsubsection{Teacher Training}

Three teacher-training sessions were conducted, along with an initial, orientation session. The orientation session was an opportunity to explain to participating teachers what the study was and why they were selected for it. Additionally, the orientation session demonstrated how the assessments worked and what types of activities and materials would be used in the future training sessions

During the first session, GES, MVP, and the teachers discussed the results of the baseline survey results as well as the performance of students, most of who were reading only at a 'letter' level. Teachers were trained on phonics instruction, letter sounds, teaching sight words, and the five components of reading: phonological awareness, phonics, fluency, vocabulary and comprehension. Training also focused on learner-centered pedagogy and classroom management, emphasizing the importance of engaging students in the lesson activities, assessing their knowledge and providing them with feedback.

The second teacher training session focused on lesson planning, scope and sequence, and differentiation. After GES, MVP, and Earth Institute teams observed teaching, it became apparent that teachers needed further support on narrowing their lesson focus and following a structured lesson plan, which would build from class to class. The session outlined the process for developing lesson plans and lesson objectives, including creating original TLM. The session also emphasized the concept of differentiation, a teaching process used to maximize student learning by improving the match between a student's individual needs and skills and the curriculum.

The final training was held as an informal troubleshooting session, in which the teachers and head teachers from the study wrote out a list of ten content-related and logistical challenges they were experiencing and members of GES and the education coordinator opened a discussion on each individual point. In the course of the meeting, concepts such as locally resourced materials, teaching sounds and letter names in logical sequence, and assessment procedures were reviewed.

${ }^{9}$ For more information, please visit http://sel.columbia.edu 


\subsubsection{Lesson Plans}

Ten sample English language lesson plans, prepared by literacy experts, were distributed to the treatment teachers in this study. Treatment teachers were encouraged to use the lesson plans in their classes, and to use the templates for future lessons. Using one lesson plan per day, the teachers were to spend at least 90 minutes covering its content. Lesson plans started at the most basic letter level, introducing 1-2 individual letters and sounds and reviewing previously taught content. It also incorporated the 'I do, we do, you do' method in which the teacher first demonstrated to the students, then worked with them, and then let them practice independently. With emphasis on phonological awareness, phonics, vocabulary and comprehension and writing, the lesson plans used sample dialogues to encourage the "I do, we do, you do" methodology. Suggested materials and reading to complement the lesson were part of the lesson plans' content, and later lessons included fluency practice.

After the initial distribution of these lesson plans, the MVP team found out that the teachers were unclear on how to use and incorporate them into their teaching. They were also unfamiliar with the presentation format. After further testing and review, the lesson plans were changed to a format more familiar to the teachers, placing all the content in a grid-like layout similar to that of the lesson plan notebooks recommended by GES.

\subsubsection{Supplementary Teaching Materials Used}

Locally created learning materials such as phonics charts were developed with the guidance of GES personnel. During the training sessions, teachers were encouraged to keep students engaged with learning materials, encouraging them to practice reading, and interacting in new ways.

Since textbooks were scarce or too complex for early readers to use, four one-page sample stories were also made available to teachers, each including two comprehension questions and a series of practice words from the text. After further discussion with some of the teachers, who asked for more content, six additional stories were developed, with more comprehension questions and vocabulary words. All the stories were bound together and distributed to schools where teachers who had participated in the first scale-up training were holding summer literacy classes.

Lastly, creative learning games and interactive materials were demonstrated and supported. Teachers were shown how to create a foldable storybook from a single sheet of paper. They were encouraged to collect bottle caps within their communities and write a letter on each, and having sets for students to use to create their own words and identify individual letters and sounds. Teachers were also provided with flashcards to teach 220 sight words, a list of the most common irregularly spelled words that fluent readers should be able to recognize instantly.

\subsubsection{Instructional Supervision}

The MVP education coordinator led weekly visits to the schools, weather permitting, alongside affiliated members of GES, the monitoring and evaluation team, and other education team partners. About once a month, team members conducted unannounced classroom observations in each of the treatment classrooms. Information collected included: classroom environment and materials, teaching techniques, and teacher interaction with students, each with detailed questions. The observer positioned him/herself at the rear or side of a classroom during a 90-minute literacy lesson, and upon completing the observation form, approached the teacher to briefly discuss feedback in private. One such observation for each of the five schools was done in the final month of study.

The role of the MVP education team was that of facilitator between teachers and students. In addition to leading meetings with teachers at their schools individually and in groups-including a final troubleshooting meeting at the MVP office - the education coordinator communicated with teachers via phone to enquire about progress. However, team members often intervened between the teachers and students at spontaneous intervals, often to clarify what the teacher was trying to say.

To sum up, the treatment included the following package: first, teacher training to improve the pedagogical skills and knowledge of teaching in English. Second, sharing test results using the Literacy Report Cards printable at http://litreportcards.modilabs.org/about.html_showed children's progress. Third, constant school supervision and corrective feedback by GES and MVP staff was a very important part of the study. Fourth, development of simple materials to support the teachers since the textbooks were way complex to be used by early readers helped the teachers immensely. Fifth, providing lesson plans in the GES approved format that the teachers were used to helped with additional guidance on the types of activities that could be done in class to improve basic literacy. Finally, it was important to make teachers realize why children should reach the next stage in their literacy ladder. This progressed from nothing $\rightarrow$ letter $\rightarrow$ word $\rightarrow$ paragraph $\rightarrow$ story. And it formed the basis of the treatment. 


\section{Results and Discussions}

\subsection{Background Characteristics of the Schools}

Table 3. Background descriptive of the schools

\begin{tabular}{|c|c|c|c|c|c|}
\hline & School Names & & & & \\
\hline Indicator list & $\begin{array}{l}\text { Aboaboso } \\
\text { D/A }\end{array}$ & Akyerekyerekrom D/A & $\begin{array}{l}\text { Apenimadi } \\
\text { D/A }\end{array}$ & Bonsaaso D/A & $\begin{array}{l}\text { Yawkasakrom } \\
\text { D/A }\end{array}$ \\
\hline \multicolumn{6}{|l|}{$T L M$} \\
\hline $\begin{array}{l}\text { Number of textbooks to } \\
\text { meet student needs }\end{array}$ & $\begin{array}{l}\text { moderately } \\
\text { insufficient }\end{array}$ & moderately insufficient & $\begin{array}{l}\text { moderately } \\
\text { insufficient }\end{array}$ & $\begin{array}{l}\text { moderately } \\
\text { insufficient }\end{array}$ & $\begin{array}{l}\text { moderately } \\
\text { insufficient }\end{array}$ \\
\hline $\begin{array}{l}\text { Notebooks } \\
\text { pens/pencils } \\
\text { student needs }\end{array}$ to meet & sufficient & sufficient & $\begin{array}{l}\text { moderately } \\
\text { insufficient }\end{array}$ & sufficient & sufficient \\
\hline $\begin{array}{l}\text { Teachers have a teacher's } \\
\text { guide for the core } \\
\text { subject(s) they teach. } \\
\text { Teachers }\end{array}$ & no & no & no & no & no \\
\hline Teacher attendance & $90 \%$ & $95 \%$ & $85 \%$ & $97 \%$ & $91 \%$ \\
\hline Proportion of teacher & & & & & \\
\hline $\begin{array}{l}\text { Force trained on reading } \\
\text { and/or } \\
\text { instruction }\end{array}$ & $37 \%$ & $13 \%$ & $21 \%$ & $29 \%$ & $29 \%$ \\
\hline \multicolumn{6}{|l|}{ School infrastructure } \\
\hline $\begin{array}{l}\text { Are there sufficient } \\
\text { desks/chairs to meet } \\
\text { students needs: }\end{array}$ & yes & no & no & yes & yes \\
\hline $\begin{array}{l}\text { Is there any power at the } \\
\text { school at the time of the } \\
\text { visit: }\end{array}$ & no & yes & yes & yes & no \\
\hline \# school toilet & & & & & \\
\hline $\begin{array}{l}\text { compartments for use by } \\
\text { anyone improved }\end{array}$ & 4 & 2 & 3 & 2 & 1 \\
\hline \# functional/improved & & & & & \\
\hline $\begin{array}{l}\text { toilet compartments } \\
\text { specific for girl: }\end{array}$ & 1 & 1 & 1 & 1 & 1 \\
\hline $\begin{array}{l}\text { Primary source of water for } \\
\text { drinking and hand-washing }\end{array}$ & $\begin{array}{l}\text { piped water to } \\
\text { yard }\end{array}$ & tube well & tube well & public tap & tube well \\
\hline $\begin{array}{l}\text { School meals are provided } \\
\text { to pupils regularly }\end{array}$ & yes & yes & yes & yes & yes \\
\hline $\begin{array}{l}\text { School meal was provided } \\
\text { to pupils during day of visit } \\
\text { Student Attendance }\end{array}$ & $67 \%$ & $50 \%$ & $75 \%$ & $75 \%$ & $100 \%$ \\
\hline $\begin{array}{l}\text { Proportion of enrolled } \\
\text { male students attending } \\
\text { class at the time of the visit }\end{array}$ & $93 \%$ & $81 \%$ & $89 \%$ & $88 \%$ & $91 \%$ \\
\hline $\begin{array}{l}\text { Proportion of enrolled } \\
\text { female students attending } \\
\text { class at the time of the visit } \\
\text { Student performance }\end{array}$ & $92 \%$ & $96 \%$ & $97 \%$ & $93 \%$ & $96 \%$ \\
\hline $\begin{array}{l}\text { Proportion of grade } 3 \\
\text { primary school students } \\
\text { who have acquired basic } \\
\text { reading skills. }\end{array}$ & $20 \%$ & $8 \%$ & $35 \%$ & $27 \%$ & $15 \%$ \\
\hline $\begin{array}{l}\text { Average reading level for } \\
\text { all schools in the cluster }\end{array}$ & $12 \%$ & $13 \%$ & $24 \%$ & $20 \%$ & $9 \%$ \\
\hline $\begin{array}{l}\text { Proportion of grade } 3 \\
\text { primary students who have } \\
\text { acquired basic numeracy }\end{array}$ & $94 \%$ & $68 \%$ & $77 \%$ & $86 \%$ & $93 \%$ \\
\hline
\end{tabular}

Source: Millennium Villages month data collection system. The figures given are averages of the past 9 months. This data is collected on a monthly basis during the school's academic year.

The school background characteristics, as given in Table 3 above show basic indicators for student attendance and academic performance, school infrastructure, teaching, materials, and teachers. This data is collected on a monthly basis from the schools. The indicators also give a good sense of the similarities between the schools. Concerning TLM, four of the five schools do not have adequate pens, pencils and notebooks for all children, all the schools had a shortage of 
textbooks, and none of the teachers have a teacher guidebook to help in teaching. All of the five schools do well in teacher attendance. School infrastructure indicators show that schools had at least one gender-separated toilet, three of the five schools had electricity most of the times, and two schools didn't have the required desks and chairs for all children. Schools had running water and provided meals. Female student attendance on the day of the visit was above $90 \%$ and upwards of $81 \%$ and for male students for all schools. Student performance data collected monthly on basic literacy and numeracy with 10 children picked randomly for P3 in the school shows that on average students do much better in numeracy skills than literacy skills ${ }^{10}$. The numeracy skills ${ }^{11}$ ranges from $68 \%$ to $94 \%$, however, the literacy rates (able to read a paragraph and a story level text at P2 level) were much lower and range from $8 \%$ to $35 \%$.

\subsection{Summary of the Teacher Background}

Table 4. Age distribution of the teachers

\begin{tabular}{ll}
\hline Ages & Number of teachers \\
\hline $23-25$ & 3 \\
$26-29$ & 5 \\
30 and higher & 2 \\
\hline Total & 10 \\
\hline
\end{tabular}

Table 5. Years of teaching experience

\begin{tabular}{lc}
\hline Categories & Years of teaching experience \\
\hline one-two years & 3 \\
three-four years & 3 \\
five to six years & 1 \\
more than six years & 3 \\
\hline Total & 10 \\
\hline
\end{tabular}

The ages of the ten teachers in this study ranged from 23 to 55 with majority of the teachers aged 26-29. All ten teachers only taught either P3 or P4.Four out of the ten teachers had a Diploma in Basic Education (DBE) and one teacher also had a Senior Secondary School Certificate ${ }^{12}$. Nine also reported having a different diploma in education. None had a master's degree in education or higher degree. Only three teachers at baseline said that they had previously participated in any teacher training related to numeracy and literacy.

\section{3 Study Results}

Students were classified as "can read" and "cannot read". The "cannot read" group includes children who could only read isolated words, identify letters, or could not read anything at all. The students classified as being in the "can read" group includes those whose highest reading level was in the paragraph or story category of the test. For the purposes of this study, MVP categorized children in the 'story' and 'paragraph' categories as 'children who can read', and children in the 'word,' 'letter' and 'nothing' categories as 'children who cannot read' in grade 2.

\footnotetext{
${ }^{10}$ Note that MVP's monthly outcome monitoring survey requires enumerators to randomly select 10 students from Primary 3 and administers the same literacy test that was used for the purposes of this survey.

${ }^{11}$ The numeracy skills include able to do addition and division.

${ }^{12}$ The options for teacher certification or qualification included- Certificate for pre-primary and nursery; Certificate "A"; Diploma in Basic Education (DBE); Senior Secondary School Certificate; Master and doctoral degree programs; In training for DBE; None of the above. More information on the teacher qualification scales for Ghana can be obtained from http://www.unilorin.edu.ng/journals/education/ije/sept1988/TEACHER\%20EDUCATION\%20AND\%20THE\%20ME W\%20EDUCATIONAL\%20SYSTEM\%20IN\%20GHANA.pdf
} 


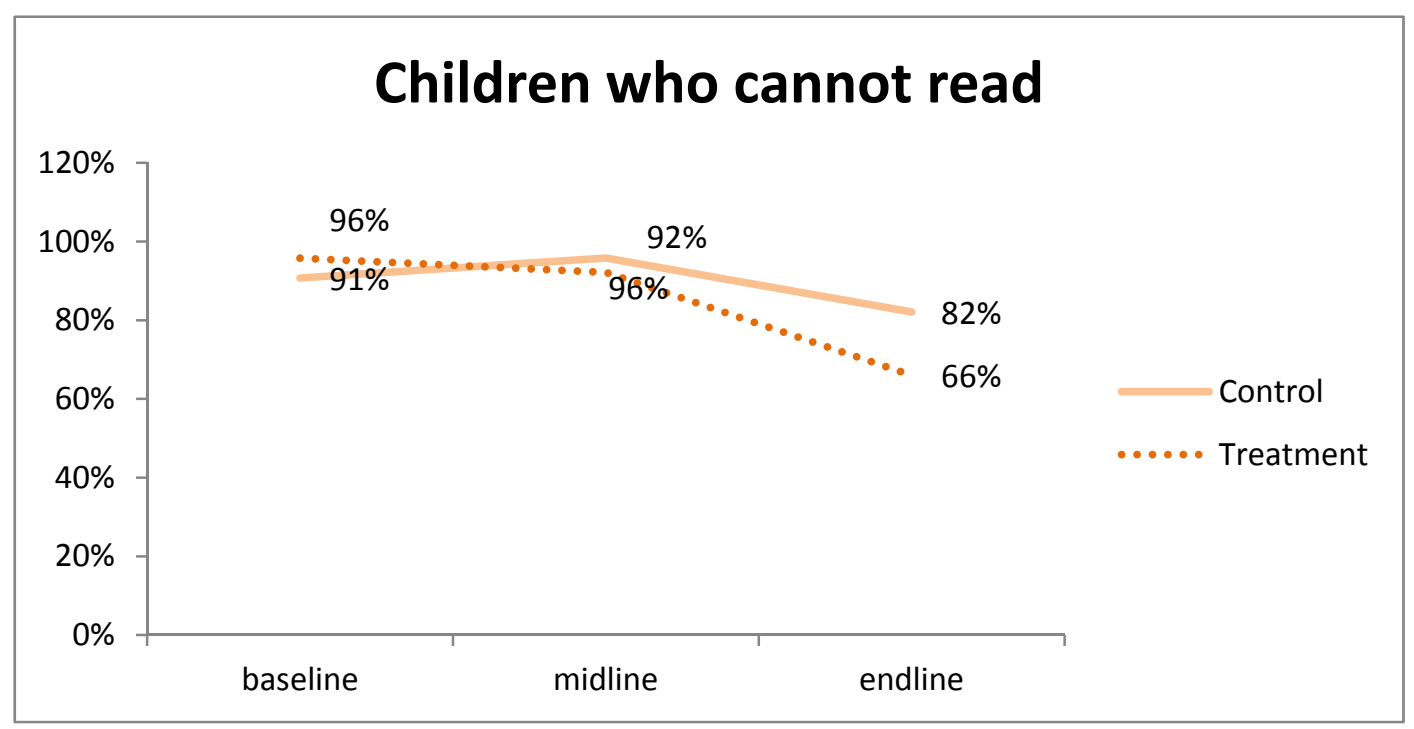

Figure 1. Overall literacy levels of children who cannot read (highest reading level: nothing, letter and words) for all children for the treatment and control groups

Note: Children have been grouped under "Cannot Read" if they are in the nothing or letter or word category. These are children who are not fluent readers.

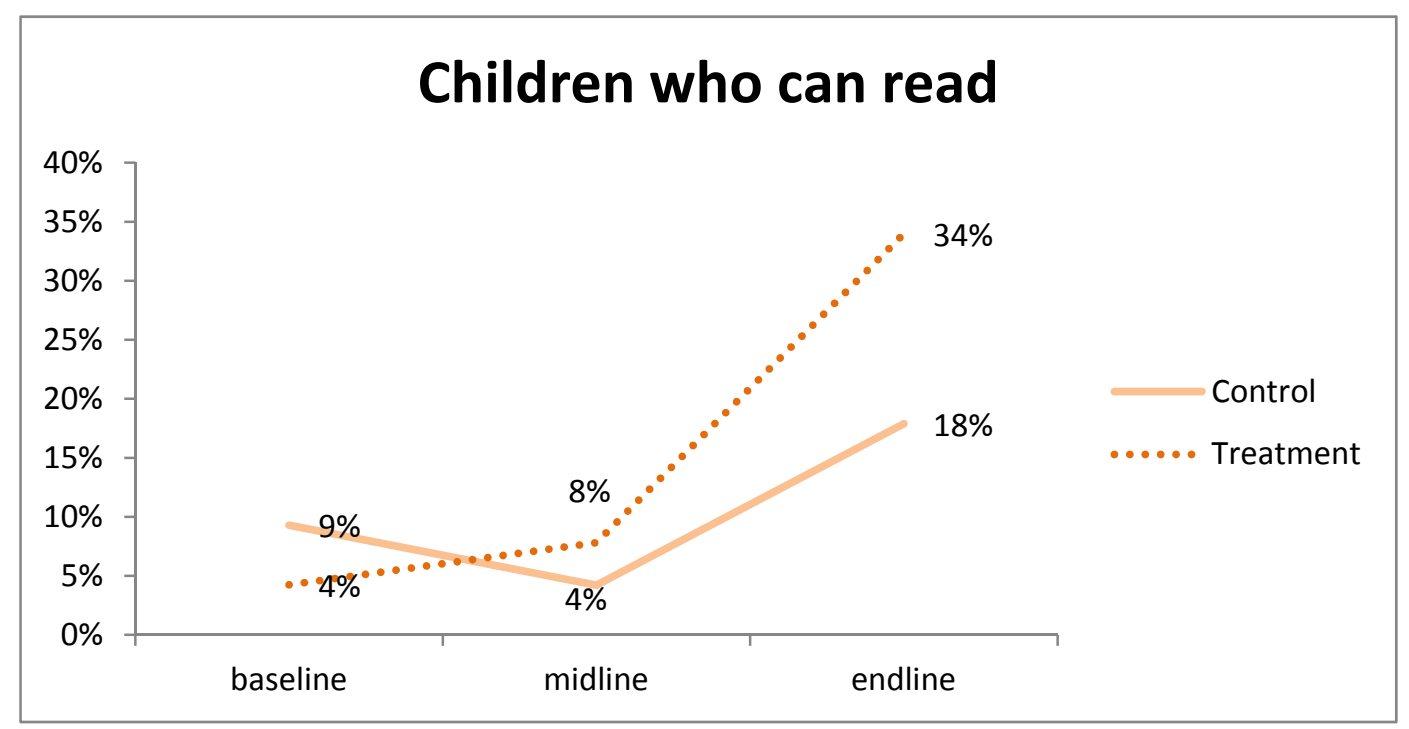

Figure 2. Overall literacy levels of 'children who can read' (highest reading level: paragraphs and story) for all children for the treatment and control groups

Note: 'Can read' is a combination of percentage of children in the paragraphs and story categories.

Figures 1 and 2 show percentages of children who can and cannot read from all the P3 and P4 children who have taken part in this study. The results show that in both treatment groups over the course of the study, the percentage of non-readers decreased and the percentage of readers increased. However, readers became more frequent in the treatment classes than in the control. Non-readers were reduced by $9 \%$ in the control group from baseline (91\%) to endline (82\%); by comparison, non-readers were reduced by $30 \%$ in the treatment group from baseline (96\%) to end line (66\%). At the end, $34 \%$ of students were classified as readers, compared to $18 \%$ for the control group.

The results for each learning category by grade for the Control and Treatment groups are given below. 
Table 6. Literacy results for all children by grade level for the Control and Treatment groups

\begin{tabular}{rcccccc}
\hline & \multicolumn{3}{c}{ Control } & \multicolumn{3}{c}{ Treatment } \\
\hline 3rd grade & baseline & midline & end line & baseline & midline & end line \\
Nothing & 4 & 2 & & & & 3 \\
Letters & 36 & 44 & 13 & 25 & 38 & 28 \\
Words & 22 & 2 & 6 & 10 & 13 & 14 \\
Paragraphs & 5 & 2 & 1 & 1 & 1 & 8 \\
Story & 3 & & & 1 & & 8 \\
All & $\mathbf{7 0}$ & $\mathbf{5 0}$ & $\mathbf{2 0}$ & $\mathbf{4 6}$ & $\mathbf{6 0}$ & $\mathbf{6 1}$ \\
\hline 4rd grade & & & & & & \\
Nothing & 4 & 1 & & 3 & 3 & 1 \\
Letters & 54 & 57 & 46 & 15 & 48 & 12 \\
Words & 7 & 8 & 13 & 2 & 5 & 6 \\
Paragraphs & 2 & 2 & 7 & 1 & 4 & 13 \\
Story & 3 & 1 & 9 & $\mathbf{7 2}$ & $\mathbf{6 8}$ & $\mathbf{4 2}$ \\
All & $\mathbf{7 0}$ & $\mathbf{6 9}$ & $\mathbf{7 5}$ & &
\end{tabular}

Note: The results show numbers of children in each category.

Figures 3 to 6 given below provide the literacy levels by each grade.

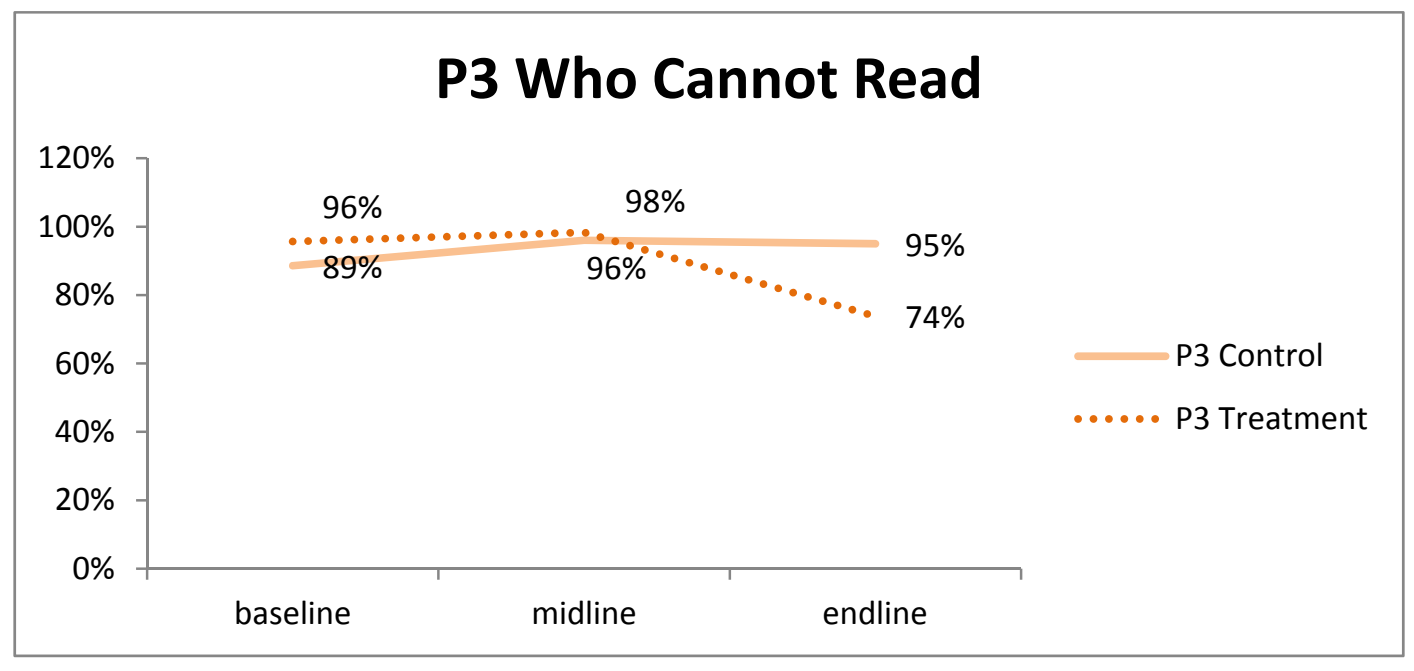

Figure 3. Primary 3 Children who cannot read

Note: 'Cannot read' is a combination of percentage of children in the nothing, letters and words categories.

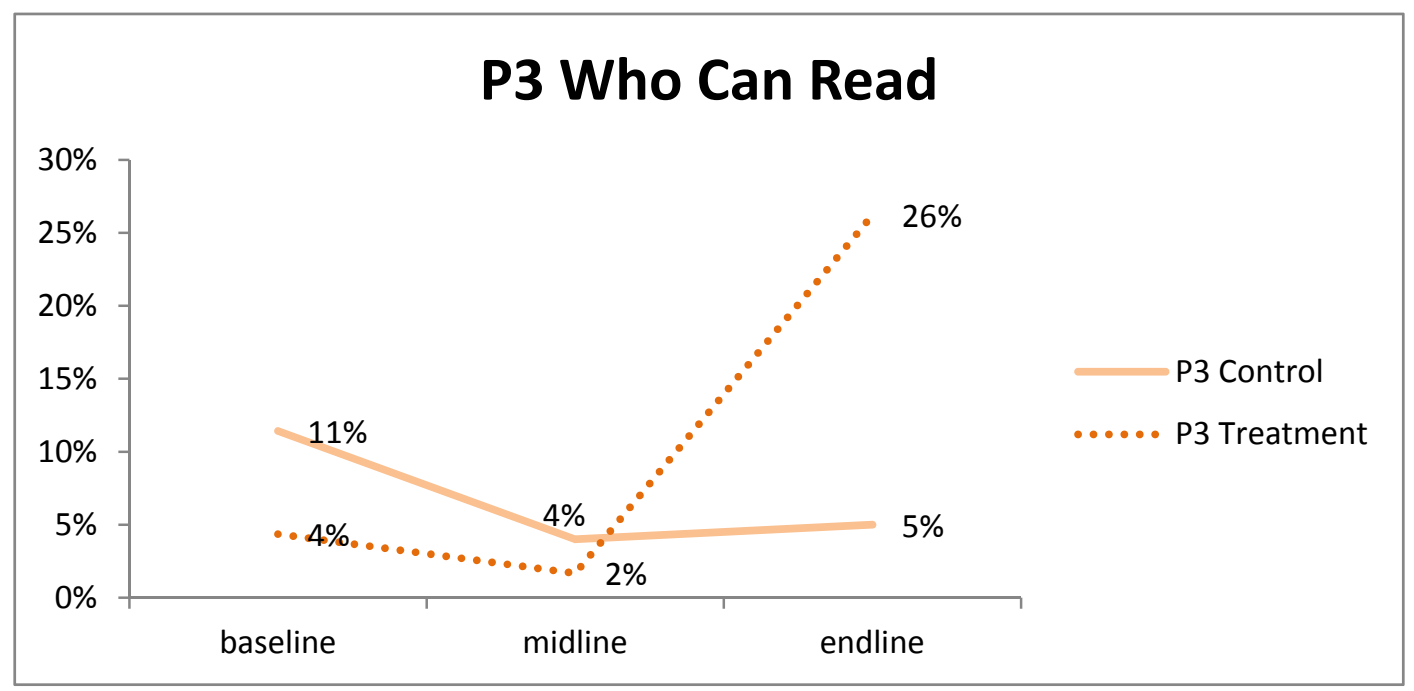

Figure 4. Primary 3 Children who can read

Note: 'Can read' is a combination of percentage of children in the paragraphs and story categories. 


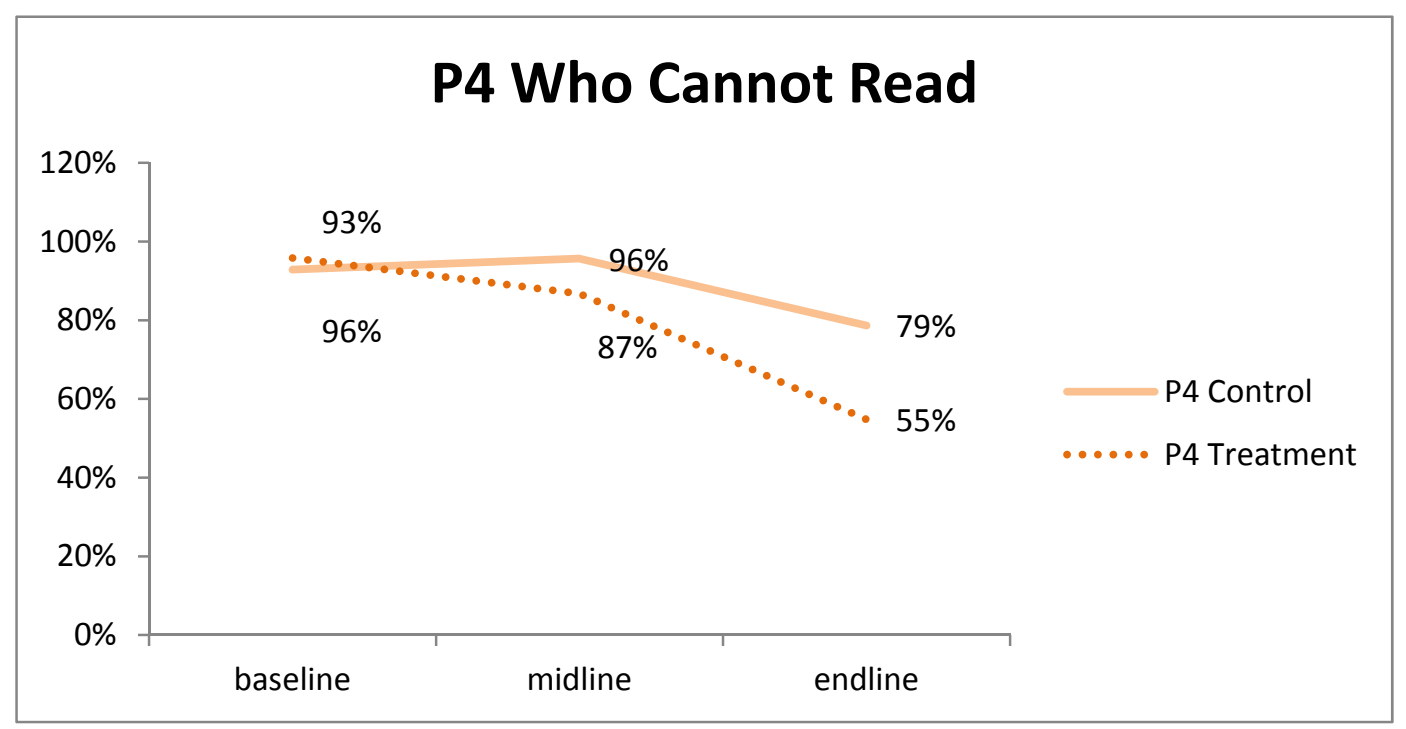

Figure 5. Primary 4 Children who cannot read

Note: 'Cannot read' is a combination of percentage of children in the nothing, letters and words categories.

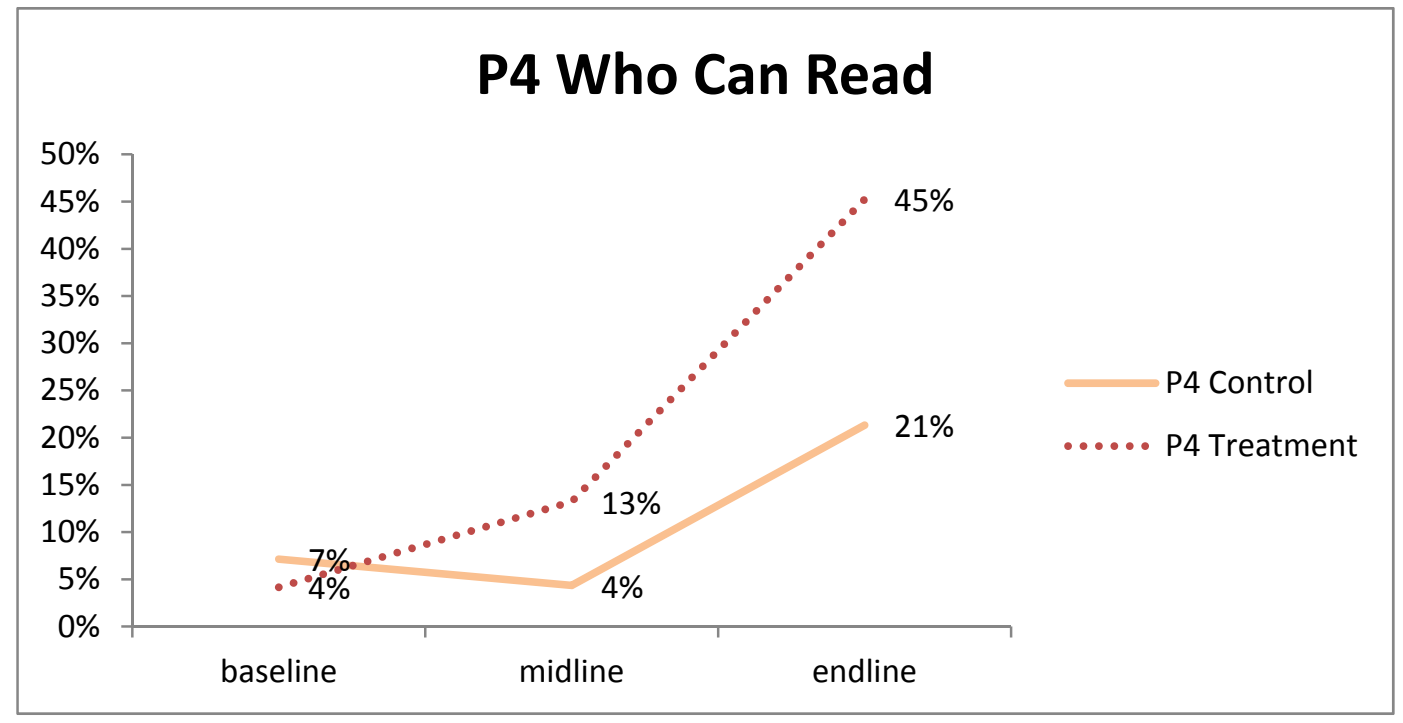

Figure 6. Primary 4 Children who Can Read

Source: Can read' is a combination of percentage of children in the paragraphs and story categories

The graphs show that, irrespective of the grades and group (control or treatment), the literacy levels were very poor at the start of the study but they improved by the end. For P3, the increase in the "can read" category for the control group was from $11 \%$ to $5 \%$, therefore an increase of $6 \%$. This increase was much steeper from $4 \%$ to $26 \%$, which is a difference of $22 \%$. For P4, the can read category showed an increase of $14 \%$ from $7 \%$ to $21 \%$ for the control group. The treatment group increased from $4 \%$ to $45 \%$ resulting in a net increase of $41 \%$. In both grades, the net increase in the "can read" category was much higher for the treatment group. Nonetheless, not all children were able to progress to the "can read" group. At the end of the study, in both the treatment and control groups, there the majority of the children were still in the "cannot read" category.

\subsection{Discussion}

The results presented above show across grades that the treatment group outperforms the control groups in the "can read" group. There is also a much steeper reduction in the "cannot read" group in the treatment group as compared to the control group. It is important to note that at the end line survey, only 20 children in the P3 control group were tested, as compared to 60 children in the treatment group. These discrepancies in testing were due to student attendance. In addition, $75 \mathrm{P} 4$ students in the control group were tested at end line as compared to $42 \mathrm{P} 4$ students in the treatment 
group. This large difference in the numbers of children tested may have affected the results. However, combining both P3 and P4 provides more robust results. Combining the total students in both treatment and control tested at end line, 95 in the control group and 103 in the treatment group make a more even sample size.

As mentioned previously, the end line data shows that $73 \%$ (146 out of the 198) children in both P3 and P4 irrespective of the group (control or treatment) are still in the "cannot read" category, which means that they were well below grade level. Only 26\% (52 out of 198) of the children were able to progress to the "can read" category. All will most likely to be promoted to the next grades, P4 and P5, without mastering even P2-level basic language competencies. This automatic promotion, also called a "social promotion" policy, in Ghana allows students to proceed to the next grade without any requirements on the grade level competencies, which might explain why children have arrived at P3 and P4 without basic reading capabilities.

The study has been able to show modest improvements in basic literacy for P3 and P4, though there is much more work to be done. Students still need to develop more complex grade-level competencies. The study merely allowed some students to make up for the learning delays that had been accumulating for some time. These delays maybe because may because of the complexity of the language itself. Since English is not a transparent orthography, spelling becomes a challenge (Abadzi, 2007). It takes more than 2.5 years for mastering English reading with regular instruction time (Ziegler \& Goswami, 2006). However in the Ghana setting, classes are irregular as well as attendance.

\subsection{Analysis of the Classroom Observations}

The classroom observations conducted during the study informed a large part of the training content. They helped the trainers identify teachers' challenges and evaluate the effectiveness of content covered in the initial training sessions. The observations also gave insight into external factors contributing to student learning. A summary table of the classroom observations is given below.

Table 7. Qualitative Field Notes Summary

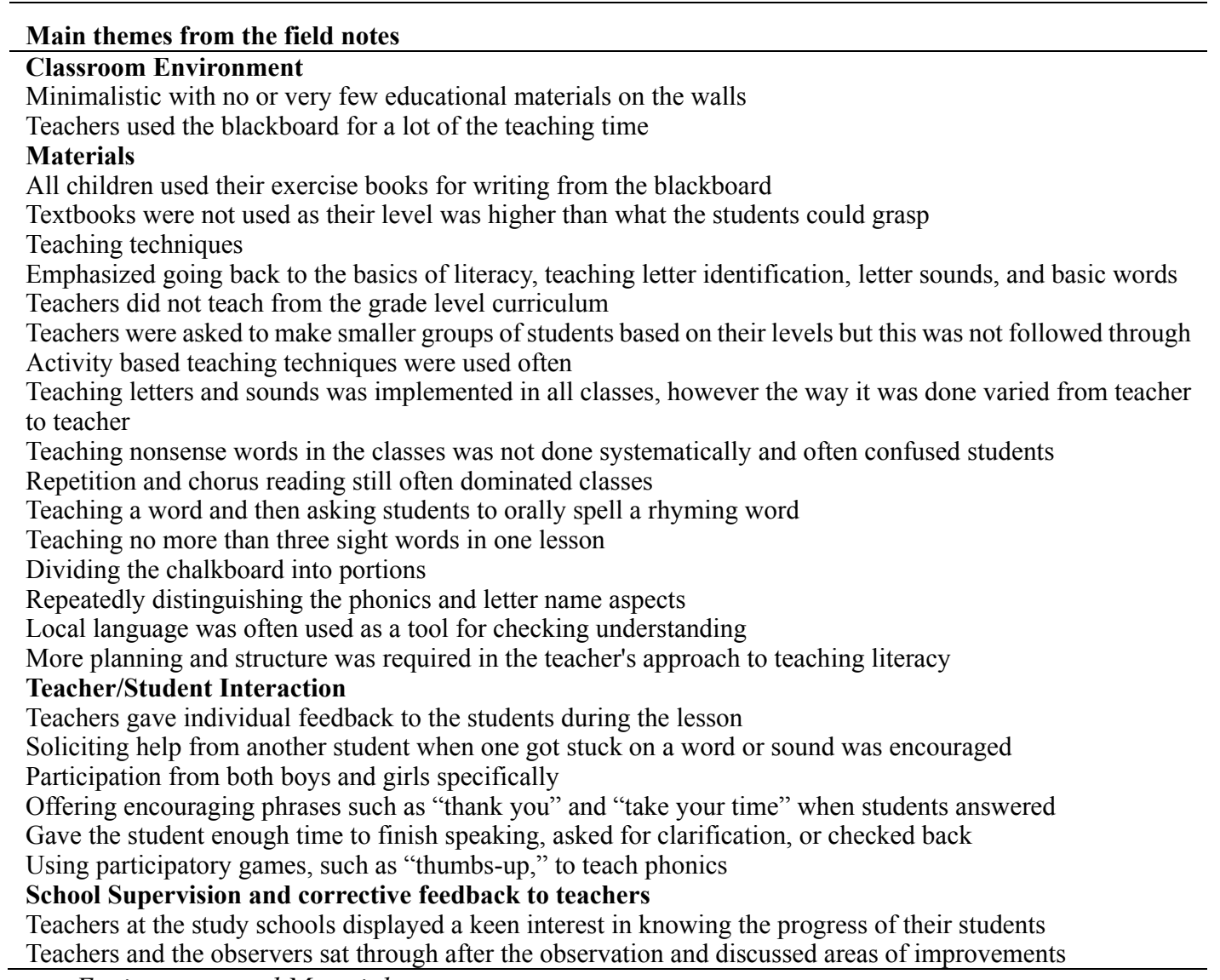

\subsection{Classroom Environment and Materials}

Classroom setup was minimal, with rows of benches and desks facing the teacher and chalkboard at the front of the classroom. Few classrooms had legible or usable displays on the walls, and many students lacked materials to use in class. Teachers often wrote the entire story or lesson on the chalkboard, and students would come up with a pointer to read. Some teachers had prepared TLM, such as sight word cards or phonics charts, to use during lessons. However, the 
display or handwriting of these cards was sometimes not clear enough for all students in the room to see.

The treatment teachers were observed teaching some material from the prepared lesson plans, and while some teachers had prepared their own lessons, their lesson plan sometimes did not reflect what they taught.There were no textbooks; exercise books were rarely used, though this was consistent with the plan for treatment teachers to suspend teaching the official curriculum.

\subsection{Teaching Techniques}

Adherence to the training techniques and TLM varied among teachers, perhaps because the teachers needed more time to adjust to them. In teaching letters and sounds, teachers demonstrated a range of practices in describing the lesson objective, with one level 3 teacher using age-appropriate and understandable definitions repeatedly, and another level 3 teacher simply writing "phonological awareness" on the chalkboard without further explanation. Another teacher was observed writing 'vowels' and 'consonants' on the chalkboard, but never defined these terms.

Repetition and chorus reading still often dominated classes. Even when an individual student was called on for an answer, the same question was posed to multiple students after the first answer and then the class was asked to repeat the answer in unison.

Nonetheless, teachers implemented several techniques. These included teaching a word and then asking students to orally spell a rhyming word, teaching no more than three sight words in one lesson, dividing the chalkboard into portions, and repeatedly distinguishing the phonics and letter name aspects.

Twi, the local language, was often used as a tool for checking understanding. If a teacher's question was met with silence, the teacher would translate to Twi until a response in English was offered. When learning letter sounds, English words written on the board as examples were intermixed with Twi words.

One of the issues that came to light during classroom observations was scope and sequence of lessons. Lessons did not appear to be building on one another, and fluctuated between basic and more complex concepts within a single lesson. These issues were addressed during the second training, but teachers will likely benefit from additional support in improving scope and sequence.

\subsection{Teacher-student Interactions}

Several teachers used methods labeled as student-centered in training sessions. For example, when a poem was being taught in class, the teacher acted out the poem to make it more engaging; it also helped the children better understand the meaning of the text. Other examples teachers demonstrated included moving around the classroom to give individual feedback during the lesson, soliciting help from another student when one got stuck on a word or sound, asking for participation from both boys and girls specifically, and offering encouraging phrases such as "thank you" and "take your time" when students answered. When dealing with incorrect responses, teachers generally gave the student enough time to finish speaking, asked for clarification, or checked back with them after the correct answer was found elsewhere. Most teachers, however, limited student participation to whole-class interactions such as asking the yes/no question "Is he right?" Applause was the main way of delivering positive reinforcement to students.

\subsection{School Supervision and Corrective Feedback to Teachers}

Teachers at the study schools displayed a keen interest in knowing the progress of their students, particularly when monitoring and evaluation teams conducted individual assessments for baseline and end line data collection. Preceding all training activities, the M\&E team held a short session to review student performance, though, at the final session, some teachers claimed they did not have access to their individual school's performance report.

Additionally, the teachers cited low literacy performance due to test anxiety induced by the use of unfamiliar materials, such as white paper, and by the presence of MVP and GES data collectors. To alleviate this anxiety, the education coordinators discussed methods for how teachers could put students at ease.

In observations conducted in May, it became clear that some teachers themselves needed further reinforcement of correct letter sounds, so during instruction they did not focus on small, irrelevant pronunciation differences. Teachers also needed to be mindful of what was written on the board, and only write things that would help students understand the concept further and that they would be able to read. Another issue was the content of each lesson. Some teachers attempted to teach too many phonemes in one lesson, or to teach similar-sounding phonemes in the same lesson, which was confusing for students.

In the weeks before the end line data was collected, classroom observations conflicted with school schedules or district assignments and were often irregularly conducted. At other meetings and trainings, teachers expressed a wish to receive more frequent feedback on their own performance. 


\section{Conclusion}

\subsection{Lessons Learnt and Future Steps}

This study shows that while providing teachers with material and training to improve basic English-language reading skills is helpful, it is not enough. Increased pedagogical support, especially for lesson planning is essential. Additionally, improving teachers' and students' own command of spoken English is highly important, as Twi was still the main medium of instruction in an English class.

Training sessions were most useful when they were adapted to teachers' needs. This allowed teachers to incorporate specific techniques that they had not tried before, such as learner-centered teaching, positive reinforcement, and giving individual student feedback.

Concerning teacher ownership of the study, involving GES and head teachers was crucial to getting teacher support and participation in this program. Furthermore, sharing the learning data with teachers built a strong case for following the study's mission of focusing on basic skills and diverging from the formal curriculum. This break from the prescribed curriculum was necessary to identify children's actual reading levels and how best to intervene to improve them. Making teaching relevant to children's abilities and using data to monitor the progress repeatedly also constituted reinforcement for teachers. Focusing on supporting each child's progression to the next level of reading helped teachers concentrate in their practice. Another helpful factor was that existing class time was used for the study, instead of extra classes or after-school remedial programs, which would have been onerous for teachers.

\section{The Way Forward}

Implementation of a program to improve literacy faces challenges both inside and outside the school community. Teachers in remote areas, many from different communities or balancing other forms of employment, are often unable or unwilling to invest time in preparing lessons and materials or enforcing basic classroom discipline. External challenges to schools in the Bonsaaso cluster include the ongoing extractive industry activity in the surrounding area, which affects regular student attendance. Weak parent-teacher relationships often contributed to a lack of home support for education, which teachers frequently attributed to fluctuations in students' performance or attendance.

The study team and teachers both identified a need to build capacity in learning and literacy methodologies. Thus, the treatment teachers consistently said that the sessions that focused on pedagogy were among the most useful, along with the sessions on TLM preparation and use.

Steps to scale-up are to begin in late 2014. The scale-up will rely on analysis of the successful and unsuccessful parts of the study, and will involve training the control teachers in techniques that were found to be effective. Data will be collected for all teachers and will be compared with results from the original treatment teachers.

While the impetus for the study was to improve students' English-language skills, the data suggest that native language mastery and literacy depend on it. The authors therefore suggest using Twi as the primary language of instruction for early grades and supporting children's reading skills in Twi, especially because native language literacy skills support second language literacy skills. This will involve focusing on fluency in Twi before reading fluency in English. Concurrently, oral English could be taught while learning to read in Twi. Therefore the language acquisition skills for the local language can help with English and the children will become literate in Grade 1.

\section{References}

Abadzi, H. (2007). Absenteeism and Beyond: Instructional Time Loss and Consequences. World Bank Policy Research Working Paper Series no. WPS4376

Abadzi, H. (2013). Literacy for All in 100 Days? A research-based strategy for fast progress in low-income countries. Global Partnership for Education Working Paper Series No. 7

Banerjee, A., Banerji, R., Duflo, E., Glennerster, R., \& Khemani, S. (2010). Pitfalls of Participatory Programs: Evidence From a Randomized Evaluation in Education in India. American Economic Journal: Economic Policy, 2(1), 1-30.

Banerjee, A., Shawn, C. S., Duflo, E., \& Linden, L. (2007). Remedying Education: Evidence from Two Randomized Experiments in India. Quarterly Journal of Economics, 122(3), 1235-1264.

Beatty, A., \& Pritchett, L. (2012). From Schooling Goals to Learning Goals: How Fast Can Student Learning Improve? http://www.cgdev.org/files/1426531_file_Beatty_Pritchett_Time_to_MLG_FINAL.pdf: Center for Global Development.

Center for Universal Education at Brookings. (2011). A global compact on learning. Taking action on education in developing 
pdf: Center for Universal Education at Brookings

Chavan, M., \& Banerji, R. (2012). The Challenge of Achieving Desirable Levels of Learning in Elementary Education. The Journal of Governance.

Das, J., Dercon, S., Habyarimana, J., Krishnan, P., Muralidharan, K., \& Sundararaman, V. (2013). School Inputs, Household Substitution, and Test Scores. American Economic Journal: Applied Economics, 5(2), 29-57.

Duflo, E., Dupas, P., \& Kremer, M. (2011). Peer Effects, Teacher Incentives, and the Impact of Tracking: Evidence from a Randomized Evaluation in Kenya. American Economic Review, 101(5), 1739-1774.

Duflo, E., Hanna, R., \& Ryan, S. (2012). Incentives work: Getting teachers to come to school. American Economic Review, 102(4), 1241-1278.

Glewwe, P., Kremer, M., \& Moulin, S. (2009). Many children left behind? Textbooks and test scores in Kenya. American Economic Journal: Applied Economics, 1(1), 112-135.

Kremer, M., Brannen, C., \& Glennerster, R. (2013). The challenge of education and learning in the developing world Science, 340(297).

Muralidharan, K. (2012). Priorities for primary education policy in India's 12th five year plans India Policy Forum 2012. New Delhi and Washington DC: National Council of Applied Economic Research, New Delhi and The Brookings Institute, Washington DC.

Mukerji, S., \& Walton, M. (2010). Learning the right lessons: Measurement, experimentation and the need to turn India's Right to Education Act upside down. New Delhi Abdul Latif Jameel Poverty Action lab (J-PAL) and Kennedy School of Government, Harvard University.

Owu-Ewie, C. (2006). The language policy of education in Ghana: A critical look at the English-only language policy of education. In: John Mugane et al. - (ed) 35th Annual Conference on African Linguistics. Cascadilla Proceedings Project. Somerville, MA.

Pritchett, L., \& Banerji, R. (2013). Schooling is not education! Using Assessment to change the politics of non-learning. A report of the Center for Global Development Study Group on Measuring Learning Outcomes.

UWEZO Kenya. (2012). Are Our Children Reading? Summary of Key Findings. Primary Facts on Learning Levels.

UWEZO Tanzania. (2011). Are Our Children Reading? Summary of Key Findings. Primary Facts on Learning Levels.

UWEZO Uganda. (2011). Are Our Children Reading? Summary of Key Findings. Primary Facts on Learning Levels.

Ziegler, J. C., \& Goswami, U. (2005). Reading Acquisition, Developmental Dyslexia, and Skilled Reading across Languages: A Psycholinguistic Grain Size Theory. Psychological Bulletin, 131, 3-29. 


\section{Appendix}

Appendix 1: Steps to do the Assessment

\section{PARAGRAPH}

Ask the child to read the paragraph. Listen carefully when the child reads. The child may read slowly, but as long as s/he is reading the text like s/he is reading a sentence rather than a string of words, categorize her/him as a "para level" child.

\begin{tabular}{|c|}
\hline $\begin{array}{l}\text { If a child is reading very slowly a an usups between words for a long time, } \\
\text { if she is reading the text like it is one word after another and therefore } \\
\text { not reading the text like she is reading a sentence, then she is not a } \\
\text { "para level" child } \rightarrow \text { You should take the child one level lower and ask } \\
\text { herhim to read words. }\end{array}$ \\
\hline WORDS \\
\hline $\begin{array}{l}\text { Ask the child to read any } 5 \text { words from the word list. Let the child choose } \\
\text { the words for themselves. If she does not choose, then point out the } \\
\text { words to her/him. } \\
\text { - If she can correctly read at least } 4 \text { out of the } 5 \text { words with ease, then } \\
\text { ask him/her to try to read the easy paragraph again } \rightarrow \text { If the child } \\
\text { can correctly read words but is still struggling with the easy } \\
\text { paragraph, mark the child as "word" level. } \\
\text { - If the child cannot correctly read at least } 4 \text { out of } 5 \text { words, then show } \\
\text { her/him the list of letters. }\end{array}$ \\
\hline LETTERS \\
\hline $\begin{array}{l}\text { Ask the child to read any } 5 \text { letters from the letters list. Let the child } \\
\text { choose the letters for themselves. If s/he does not choose, then point out } \\
\text { letters to her/him. } \\
\text { - If s/he can correctly recognize at least } 4 \text { out of the } 5 \text { letters with } \\
\text { ease, then ask him/her the list of words again } \rightarrow \text { If the child can } \\
\text { recognize } 4 \text { out of } 5 \text { letters but cannot read words, mark the child as } \\
\text { "letter" level. } \\
\text { - If the child cannot recognize at least } 4 \text { out of } 5 \text { letters from the letters } \\
\text { in the list, then mark herlhim as "nothing" level child. }\end{array}$ \\
\hline
\end{tabular}

Source: UWEZO

Once you have uecided that this child is a "para" level child, ask the child to read the story.

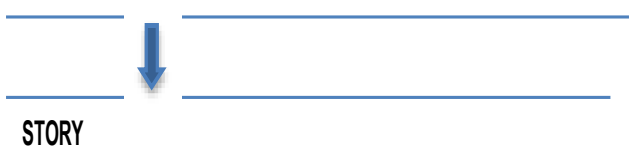

- If the child reads the story fluently, with ease and speed, mark herl him as a "story" level child (or a child who can read a Standard 2 level text).

- If the child is unable to read the story fluently and stops a lot, mark the child as a "para" child. 
Appendix 2. Sample test in English

Story

Paragraphs

\begin{tabular}{|c|c|}
\hline $\begin{array}{c}\text { Salma is a little girl. } \\
\text { She had a little doll. } \\
\text { She loved playing with the doll. } \\
\text { One day the doll fell from her hand to the } \\
\text { floor. }\end{array}$ & $\begin{array}{c}\text { Dasana goes to school. } \\
\text { It is very far away. }\end{array}$ \\
He takes a bus to school. The bus takes \\
ft broke into several pieces. \\
Salma was very sad. \\
She cried a lot.
\end{tabular}

Figure A. side one of a literacy test
Letter Recognition
Word Recognition

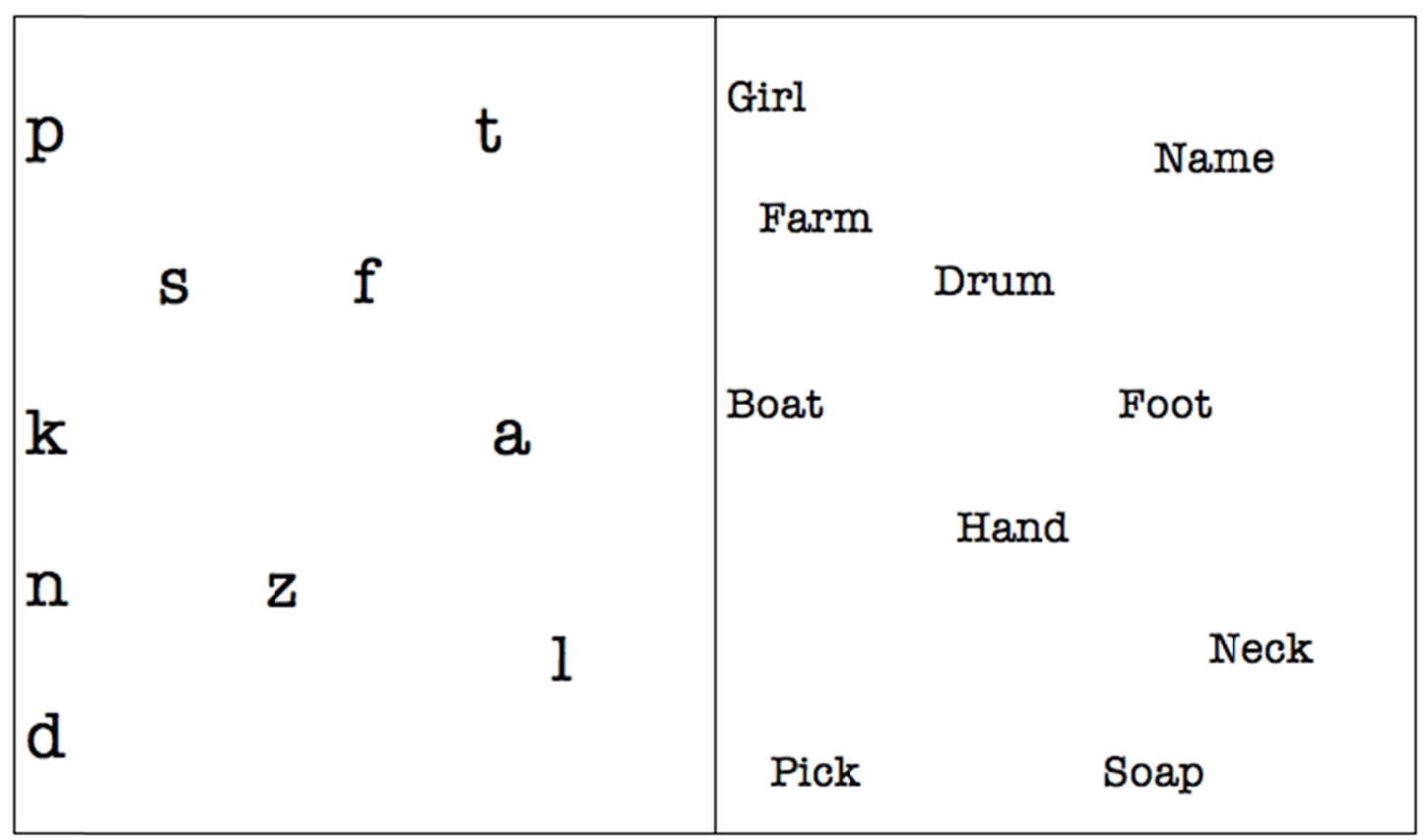

Figure B. side two of a literacy test

\section{(cc) EY}

This work is licensed under a Creative Commons Attribution 3.0 License. 